\title{
71 Sport und Optimierung der Immunabwehr
}

\author{
(C) Springer-Verlag GmbH Deutschland, ein Teil von Springer Nature 2018 \\ D. Mathias, Fit und gesund von 1 bis Hundert \\ https://doi.org/10.1007/978-3-662-56307-6_71
}

Moderat betriebenes Ausdauertraining im aeroben Bereich fördert die Leistungs- und Regenerationsbereitschaft der Immunabwehr.

Die Infektraten sind vermindert und die Symptomschwere herabgesetzt. Zwischen Ausdauertraining und Immunschutz besteht eine J-förmige Beziehung. Das niedrigste Infektionsrisiko haben gemäßigt trainierende Breitensportler. Inaktivität und mehr noch Hochleistungssport steigern das Infektionsrisiko. Für ältere Sportler ist ein erweitertes Wochenpensum von 3-5 Stunden, verteilt auf 4-5 Trainingseinheiten, ideal. Jüngere Menschen passen sich immunverträglich deutlich höheren aeroben Belastungen an.

Negative Veränderungen in der Immunabwehr durch gelegentlich übertriebene körperliche Akutbelastungen sind bei Einhaltung ausreichender Erholungszeiten reversibel. Deren Dauer sollte jedoch nicht unterschätzt werden, nach schweren Belastungen sind für eine vollständige Regeneration 3-4 Tage anzusetzen. Die Regenerationsfähigkeit ist dabei umso besser ausgeprägt, je stärker die aerobe Ausdauerfähigkeit trainiert ist.

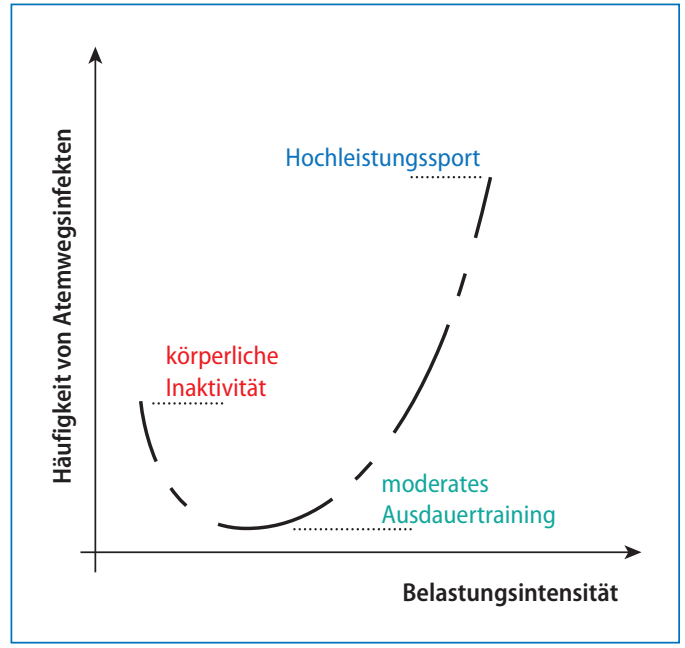

- Abb. 71.1 Die Sportdosis bestimmt den Immunschutz

Ohne genügend lange Erholungszeiten kommt es zur Erschöpfung des Immunsystems. 